\title{
Bei hartnäckigem Nasenbluten erst endoskopieren
}

Die Quelle von therapierefraktärer Epistaxis liegt häufig im oberen Teil der Nasenhöhle. Daher kann die endoskopisch geleitete Elektrokauterisation als Therapie der ersten Wahl gelten.
S o lautet zumindest die Empfehlung von $\mathrm{HNO}-$ Ärzten der Universitätsklinik Shanghai, die retrospektiv die Akten von 265 Patienten mit idiopathischer Epistaxis ausgewertet haben. Bei den Patienten war mittels Rhinoskop keine Lokalisation der Blutung möglich gewesen und mindestens ein Therapieversuch mit vorderer und hinterer Nasentamponade fehlgeschlagen. Alle Patienten wurden in Lokalanästhesie endoskopiert. Wenn die Blutungsquelle ausfindig gemacht werden konnte, wurde das Gefäß mittels Elektrokauter verödet. Bei nicht exakt lokalisierbarem Ursprung oder massiver Blutung wurde selektiv tamponiert.

Die Blutungen kamen - in absteigender Häufigkeit - aus dem oberen Septum im Bereich der Riechrinne $(39,2 \%)$, dem unteren Nasengang (27,5\%), dem Recesmittleren Nasengang (5,3\%). Bei knapp $20 \%$ der Patienten konnte der Blutungsort nicht identifiziert werden. Der häufigste Ursprung bei Patienten über 50 Jahren war der Sulcus olfactorius, bei Patienten unter 50 Jahren der Meatus inferior. Diese Stellen sollten daher altersabhängig zuerst inspiziert werden, so der Rat der Studienautoren. sus sphenoethmoidalis $(6,0 \%)$ und dem
Bei allen Blutungen in unterem oder war die Elektrokauterisation erfolgreich. Dies war auch der Fall bei zwei Patienten, bei denen zuvor bereits eine Ligatur bzw. eine Embolisation der A. maxillaris vorgenommen worden war. Bei Blutungen im Recessus musste wegen nicht exakt lokalisierbaren Ursprungs öfter tamponiert werden. Ernsthafte Komplikationen traten in keinem Fall auf.

Fazit: Aufgrund der Studienergebnisse empfehlen die chinesischen HNO-Ärzte dringend, bei idiopathischer therapierefraktärer Epistaxis zuerst zu endoskopieren, bevor man erneut tamponiert. Mehrfache Tamponaden seien schmerzhaft und oft nutzlos. Wenn möglich, sollte daher sogar schon vor der ersten hinteren Tamponade endoskopiert werden. Klar umgrenzte Blutungsquellen sollten dann mit dem Elektrokauter ausgeschaltet werden. Nur wenn die Blutung nicht exakt verortet werden kann, sollte selektiv tamponiert werden.

Dr. Beate Schumacher

Liu Y et al. Management of intractable epistaxis: endoscopy or nasal packing? J Laryngol Otol 2012; 126: 482-6 mittlerem Nasengang oder Riechrinne

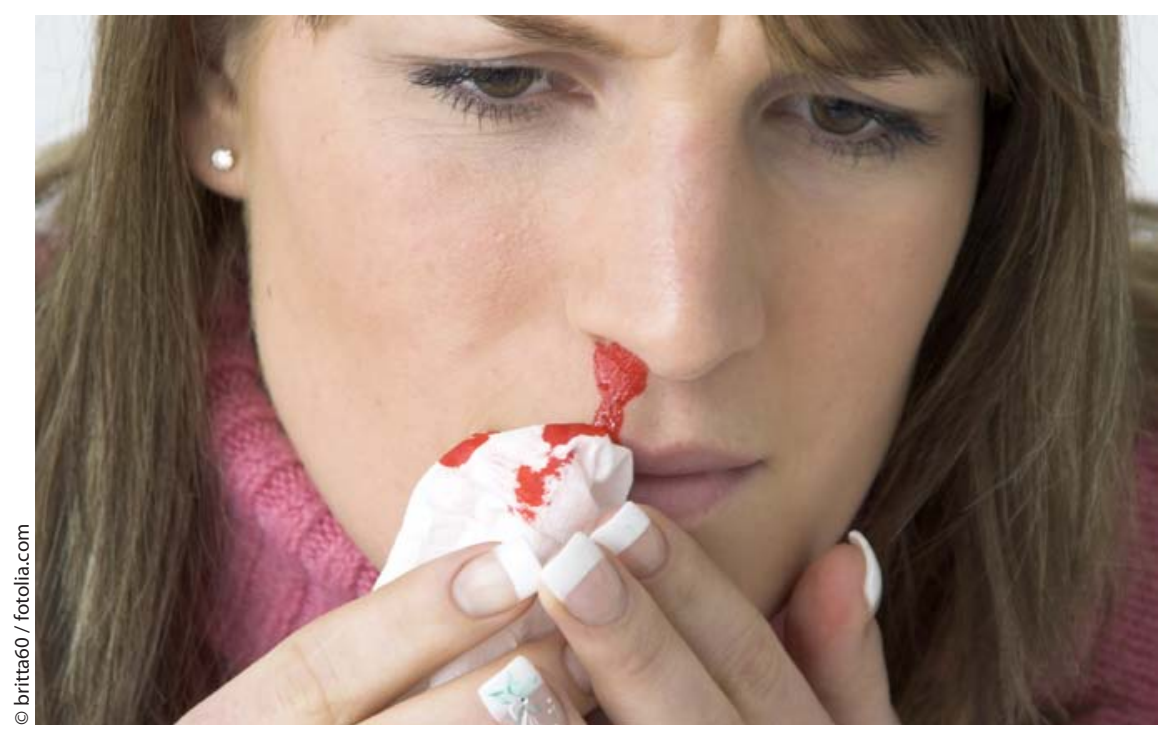

Bei jüngeren Patienten liegt die Quelle therapierefraktärer Blutungen oft im Meatus inferior.

\section{Sommer, Sonne, trockene Nase?}
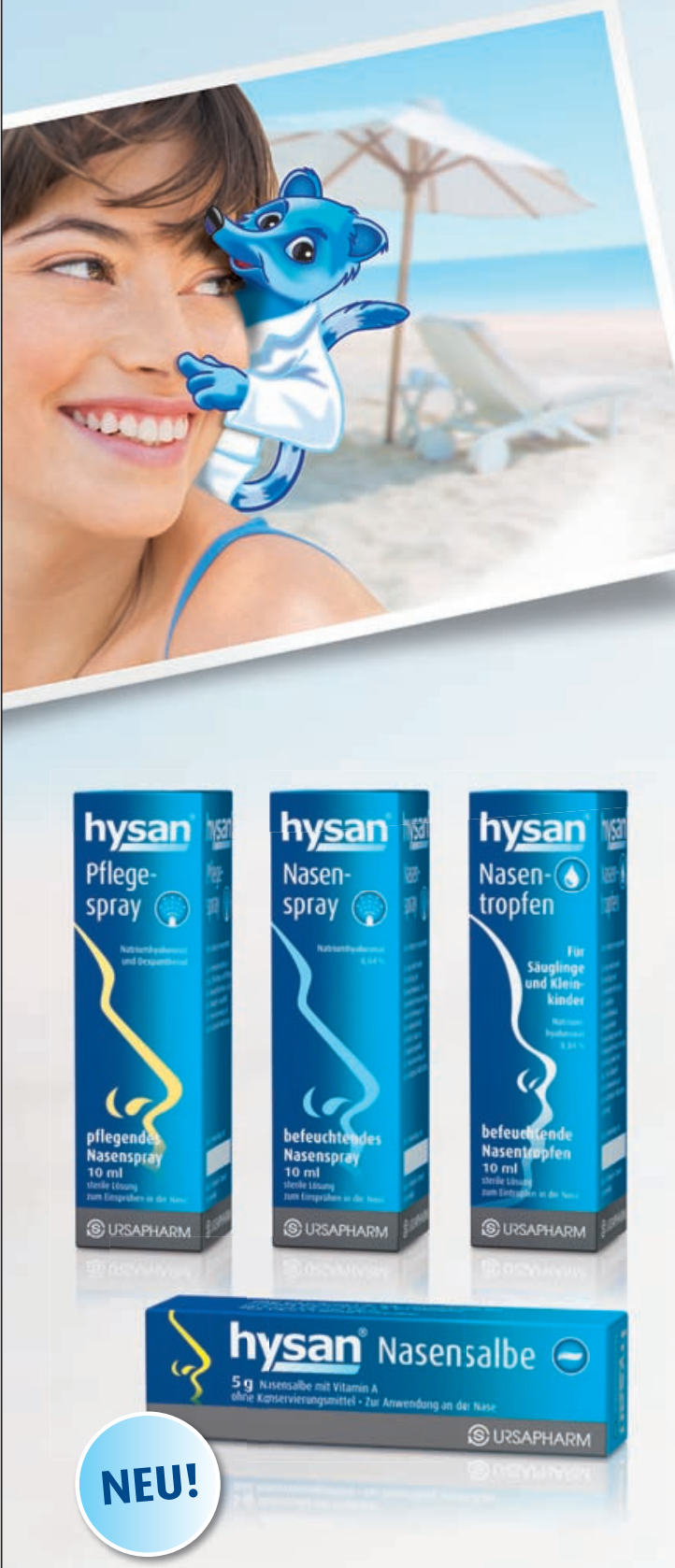

- bei trockenen und gereizten Nasenschleimhäuten

- effektive Pflege, lang anhaltende Befeuchtung

- exklusiv in der Apotheke erhältlich 